Research

\title{
Lipoprotein lipase expression, serum lipid and tissue lipid deposition in orally-administered glycyrrhizic acid-treated rats Wai Yen Alfred Lim ${ }^{1}$, Yoke Yin Chia ${ }^{1}$, Shih Yeen Liong ${ }^{1}$, So Ha Ton*1, Khalid Abdul Kadir ${ }^{2}$ and Sharifah Noor Akmal Syed Husain ${ }^{3}$
}

\begin{abstract}
Address: ${ }^{1}$ School of Science, Monash University Sunway Campus, Jalan Lagoon Selatan, Bandar Sunway 46150, Selangor Darul Ehsan, Malaysia, ${ }^{2}$ School of Medicine and Health Sciences, Monash University Sunway Campus, Jalan Lagoon Selatan, Bandar Sunway 46150, Selangor Darul Ehsan, Malaysia and ${ }^{3}$ Cytopathology and Cytogenetics Unit, Department of Pathology, Universiti Kebangsaan Malaysia Medical Centre, Jalan Yaacob Latif, Bandar Tun Razak, Cheras 56000, Kuala Lumpur, Malaysia

Email: Wai Yen Alfred Lim - wylim3@student.monash.edu; Yoke Yin Chia -ykchi4@student.monash.edu; Shih Yeen Liong - sylio1@student.monash.edu; So Ha Ton* - ton.so.ha@sci.monash.edu.my;

Khalid Abdul Kadir - khalid.kadir@med.monash.edu.my; Sharifah Noor Akmal Syed Husain - sharifah@mail.hukm.ukm.my

* Corresponding author
\end{abstract}

Published: 29 July 2009

Lipids in Health and Disease 2009, 8:3I doi:I0.1 I86/I476-5IIX-8-3 I

This article is available from: http://www.lipidworld.com/content/8/I/3I

(c) 2009 Lim et al; licensee BioMed Central Ltd.

This is an Open Access article distributed under the terms of the Creative Commons Attribution License (http://creativecommons.org/licenses/by/2.0), which permits unrestricted use, distribution, and reproduction in any medium, provided the original work is properly cited.

\begin{abstract}
Background: The metabolic syndrome (MetS) is a cluster of metabolic abnormalities comprising visceral obesity, dyslipidaemia and insulin resistance (IR). With the onset of IR, the expression of lipoprotein lipase (LPL), a key regulator of lipoprotein metabolism, is reduced. Increased activation of glucocorticoid receptors results in MetS symptoms and is thus speculated to have a role in the pathophysiology of the MetS. Glycyrrhizic acid (GA), the bioactive constituent of licorice roots (Glycyrrhiza glabra) inhibits I I $\beta$-hydroxysteroid dehydrogenase type I that catalyzes the activation of glucocorticoids. Thus, oral administration of GA is postulated to ameliorate the MetS.
\end{abstract}

Results: In this study, daily oral administration of $50 \mathrm{mg} / \mathrm{kg}$ of GA for one week led to significant increase in LPL expression in the quadriceps femoris $(p<0.05)$ but non-significant increase in the abdominal muscle, kidney, liver, heart and the subcutaneous and visceral adipose tissues $(p>0.05)$ of the GA-treated rats compared to the control. Decrease in adipocyte size $(p>0.05)$ in both the visceral and subcutaneous adipose tissue depots accompanies such selective induction of LPL expression. Consistent improvement in serum lipid parameters was also observed, with decrease in serum free fatty acid, triacylglycerol, total cholesterol and LDL-cholesterol but elevated HDLcholesterol $(p>0.05)$. Histological analysis using tissue lipid staining with Oil Red $O$ showed significant decrease in lipid deposition in the abdominal muscle and quadriceps femoris $(p<0.05)$ but non-significant decrease in the heart, kidney and liver $(p>0.05)$.

Conclusion: Results from this study may imply that GA could counteract the development of visceral obesity and improve dyslipidaemia via selective induction of tissue LPL expression and a positive shift in serum lipid parameters respectively, and retard the development of IR associated with tissue steatosis. 


\section{Background}

Lipoprotein lipase (LPL) is the major enzyme responsible for the hydrolysis of circulating triacylglycerol (TAG) moiety of both classes of TAG-rich lipoproteins; the chylomicrons and very-low-density lipoprotein (VLDL), generating free fatty acids (FFA) that are either oxidized in the muscles or re-esterified in the adipose tissues, and glycerol that is returned to the liver. LPL plays a central role in overall lipoprotein metabolism, where (i) the successive interaction of VLDL with LPL generates the lowdensity lipoproteins (LDL) that are involved in forward cholesterol transport and (ii) the remnant lipoprotein particles so formed from LPL catalysis contributes to the maturation of high-density lipoprotein (HDL) precursors, the latter of which is then involved in reverse cholesterol transport $[1,2]$. Perturbation in LPL activity could therefore lead to significant metabolic consequences and LPL has been implicated in pathophysiological conditions characterized by marked hypertriglyceridaemia, such as that observed in the metabolic syndrome (MetS).

The MetS refers to a constellation of metabolic abnormalities characterized by the co-existence of insulin resistance (IR), visceral obesity, hyperglycaemia, hypertension and dyslipidaemia. The syndrome has become a recognizable clinical cluster of risk factors that are predictive of the progression to cardiovascular disease and type 2 diabetes mellitus (T2DM) [3]. Both visceral obesity and IR are recognized as the major determinants in the development of the MetS [4] and in fact, over $80 \%$ of individuals with T2DM are obese and virtually all are insulin resistant [5]. Differing definitions of the syndrome have been put forward by various global health agencies such as the World Health Organization (WHO), the National Cholesterol Education Program Adult Treatment Panel III (NCEP ATP III) and the International Diabetes Federation (IDF) but all such definitions point to a common agreement that the syndrome results in increased atherogenesis and death from myocardial infarction [4]. Thus, increased attention has been channeled to the improvement of lipid abnormalities characteristic of the MetS.

Dyslipidaemia, the hallmark of the MetS which is manifested in the more severe form in T2DM, is characterized by (i) increased flux of FFA, (ii) elevated TAG level (hypertriglyceridaemia), (iii) reduced HDL level and (iv) a predominance of small, dense LDL. Elevated plasma FFA is viewed as the primary defect leading to the development of dyslipidaemia [6,7] and IR [8]. With the ensuing IR, LPL expression is reduced and LPL activity becomes diminished $[9,10]$. This amplifies the extent of the hypertriglyceridaemia by favouring the accumulation of TAGrich chylomicrons and VLDL in the circulation. The increase in small, dense LDL and low HDL is secondary to this elevated TAG level, where through the action of cholesteryl ester transfer protein (CETP), TAG enrichment of both the HDL and LDL particles occurs. TAG-rich LDL particles are good substrate to be acted upon by hepatic lipase (HL), producing a population of small, dense, lipid-poor LDL. Similarly, HL-mediated hydrolysis of TAG-rich cholesterol-poor HDL leads to an accelerated degradation of apo A-I, the major protein of HDL. This causes the HDL to be rapidly cleared from the plasma $[6,7,11]$. In addition to such serum lipid perturbations, studies have also indicated that tissue lipid accumulation is associated with obesity-related IR and T2DM where both conditions are associated with increased tissue lipid $[12,13]$.

Increased activation of glucocorticoid receptors has been implicated in the development of MetS symptoms such as visceral obesity and hyperlipidemia. Pharmacological inhibition of the enzyme $11 \beta$-hydroxysteroid dehydrogenase type 1 (11 $\beta$-HSD1) that acts to regenerate active glucocorticoids from inactive 11-keto metabolites has been proposed as a therapeutic target for the treatment of MetS following the association of such inhibition with a cardioprotective lipid profile $[14,15]$. Glycyrrhizic acid (GA), the primary bioactive constituent of the roots of the shrub Glycyrrhiza glabra and its pharmacologically active metabolite glycyrrhetic acid (GE) act as potent, non-selective inhibitors of both isoforms of $11 \beta$-HSD [16,17]. To date however, the effects of orally-administered GA on LPL expression and on the modulation of serum lipid and tissue lipid deposition have yet to be conducted. The objectives of this study are therefore to determine and compare each of these parameters between GA-treated and nontreated rats following daily oral administration of GA for one week in the former.

\section{Results \\ GA treatment led to increase in LPL expression of all studied tissues}

LPL expression in the GA-treated rats was increased in all studied tissues (Figure 1), of which included the heart, liver, kidney, quadriceps femoris (QF), abdominal muscle (AM), visceral adipose tissue (VAT) and subcutaneous adipose tissue (SAT). The QF demonstrated the highest increase with a fold difference of $2.02 \pm 0.89$, representing a significant $102 \%$ increase $(p<0.05)$. This was followed by the AM $(1.87 \pm 1.61$ fold; $87 \%$ increase $)$, kidney $(1.43$ \pm 0.93 fold; $43 \%$ increase), liver $(1.29 \pm 1.01$ fold; $29 \%$ increase $)$ and the VAT ( $1.08 \pm 0.48$ fold; $8 \%)$; all of which exhibited no significance difference between the control and GA-treated group $(p>0.05)$. Increase in LPL expression was similar in the heart and SAT $(1.04 \pm 0.48 ; 4 \%$ increase) but these were not significant $(p>0.05)$.

\section{GA treatment reduced the size of adipocytes}

Mean area of both VAT and SAT adipocytes showed nonsignificant decrease in the GA-treated group compared to the control $(p>0.05)$ (Figure 2$)$. In the VAT, mean adi- 


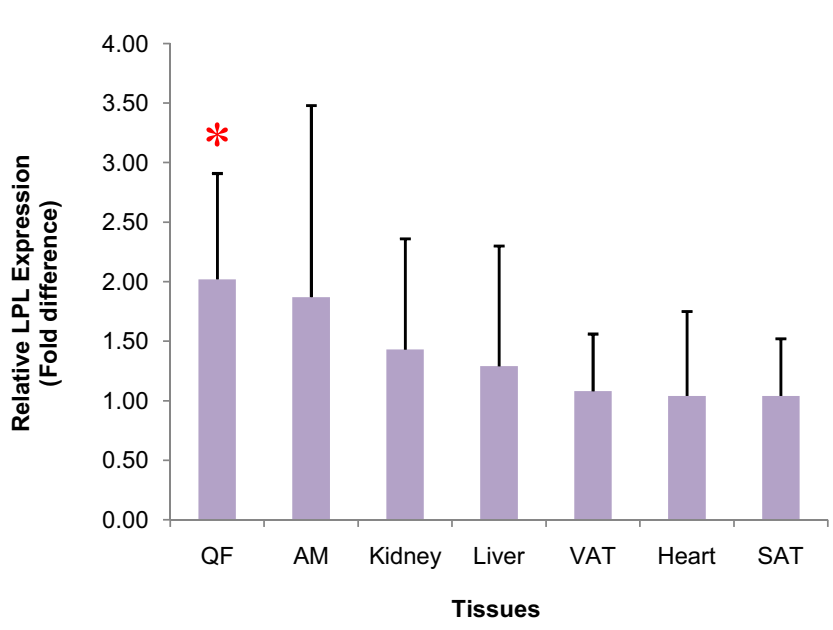

Figure I

Fold difference in tissue LPL expression of the GAtreated group. Relative tissue LPL expression following GA treatment is shown in decreasing order. In this analysis, $\beta$ actin (BAC) gene was used as the endogenous reference, GA-treated group as the target and control group as the calibrator. ${ }^{*}$ denotes $p<0.05$.

pocyte area in the control group was $1449.96 \pm 156.58$ $\mu \mathrm{m}^{2}$ while that in the treated group was $1206.58 \pm 239.48$ $\mu \mathrm{m}^{2}$. In the SAT, mean adipocyte area was $1419.91 \pm$ $141.14 \mu \mathrm{m}^{2}$ in the control group, compared to a mean of $1161.18 \pm 143.26 \mu \mathrm{m}^{2}$ in the treated group. These represented a $16.79 \%$ and $18.22 \%$ reduction in the area of adi-

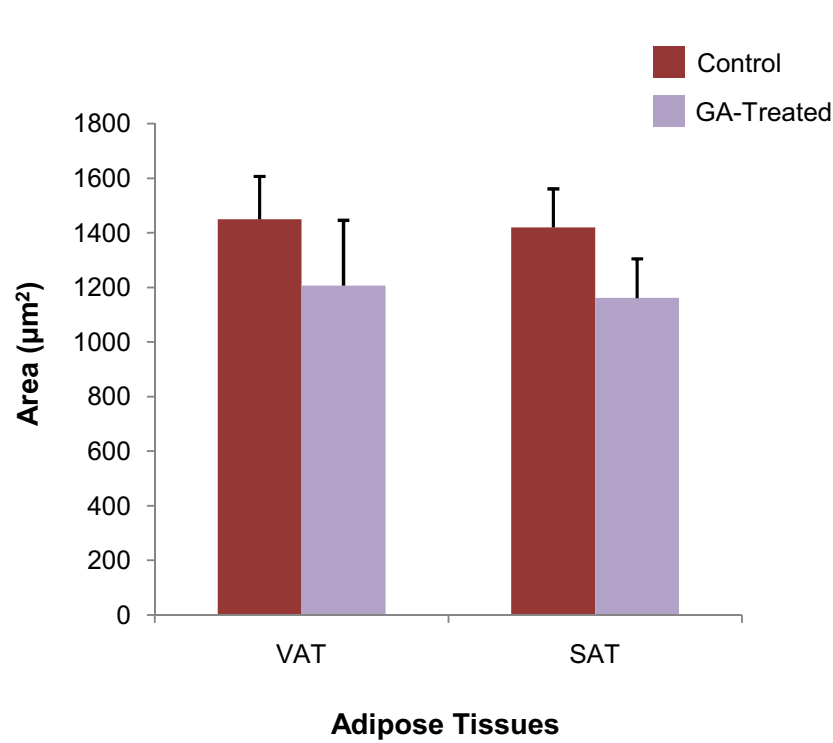

Figure 2

Mean area of adipocytes $\left(\mu \mathrm{m}^{2}\right)$ of control and GAtreated rats. Size of adipocytes demonstrated a decrease in both the VAT and SAT depot after seven days of oral GA administration $(p>0.05)$.

pocytes in VAT and SAT respectively. Sections of these tissues are shown in Figure 3.

\section{GA treatment led to improvement in all serum lipid parameters}

Consistent improvement in all serum lipid parameters were observed in the GA-treated rats relative to the control $(p>0.05)$ (Figure 4$)$. Mean serum TAG showed a $14.73 \%$ reduction (control, $1.29 \pm 0.31 \mathrm{mmol} / \mathrm{L}$; treated, $1.10 \pm$ $0.27 \mathrm{mmol} / \mathrm{L}$ ) while that of total cholesterol charted a reduction of $12.99 \%$ (control, $3.31 \pm 0.60 \mathrm{mmol} / \mathrm{L}$; treated, $2.88 \pm 0.43 \mathrm{mmol} / \mathrm{L})$ and that of LDL-cholesterol a $36.96 \%$ reduction (control, $1.38 \pm 0.34 \mathrm{mmol} / \mathrm{L}$; treated, $0.87 \pm 0.27 \mathrm{mmol} / \mathrm{L})$. HDL-cholesterol on the other hand was elevated by $11.85 \%$ (control, $1.35 \pm 0.19$ $\mathrm{mmol} / \mathrm{L}$; treated, $1.51 \pm 0.47 \mathrm{mmol} / \mathrm{L})$. Serum FFA also exhibited a similar trend of improvement with a reduction of $8.51 \%$ in the treated group (control, $0.47 \pm 0.07 \mathrm{mmol} /$ $\mathrm{L}$; treated, $0.43 \pm 0.07 \mathrm{mmol} / \mathrm{L})$.

\section{GA treatment reduced tissue lipid deposition}

Lipid deposition demonstrated a decrease across all studied tissues in the GA-treated group (Figure 5). Levels of lipid deposition was highest in the liver and recorded a $21.86 \%$ decrease (control, 582.44 (23.50-1939.66) AU; treated, 55.14 (23.13-1830.91) AU) following GA treatment. The kidney demonstrated a $25.11 \%$ decrease (control, 137.54 (11.55-392.10) AU; treated, 103.00 (13.10228.00) AU). No significant difference between the control and treated groups were observed in both tissues $(p>$

\section{Control}
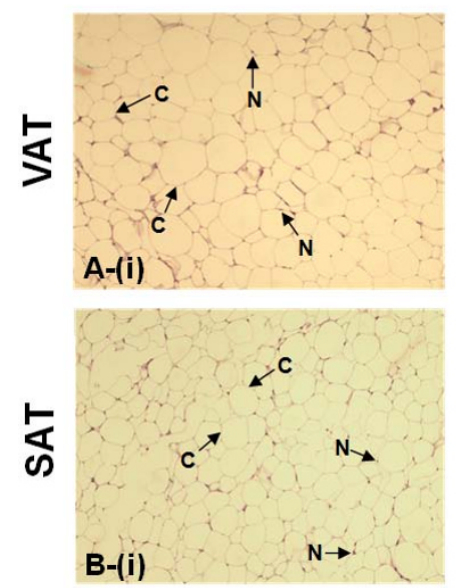

\section{Figure 3}

H\&E-stained adipose tissues. Representative sections of H\&E-stained (A) VAT and (B) SAT in (i) control and (ii) GAtreated rats at $100 \times$ magnification. The adipocytes appear as empty, unstained vacuoles with the nucleus compressed to one side of the cell while the cytoplasm is reduced to only a small rim at the periphery of the cell. Arrows indicate examples of cytoplasm (C) and nucleus (N). 


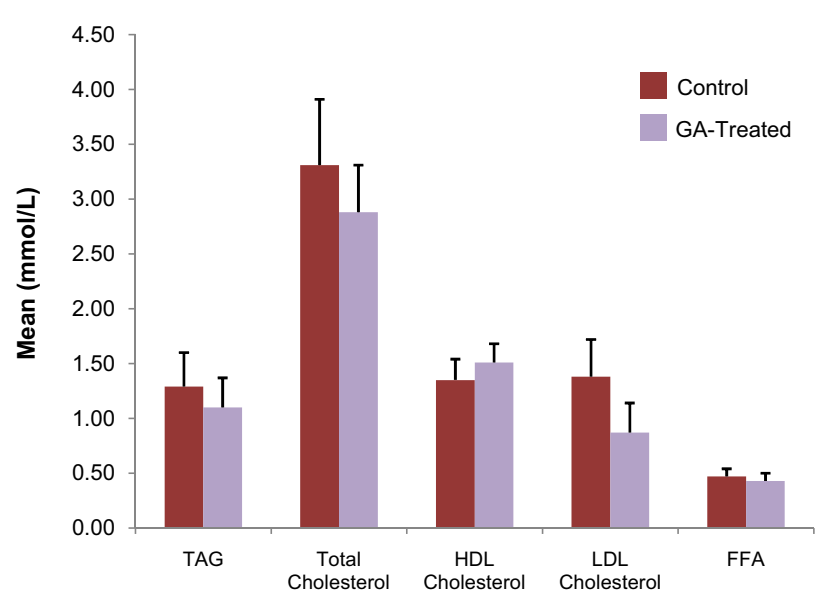

Serum Lipid Parameters

\section{Figure 4}

Serum lipid of control and GA-treated rats. Mean serum TAG, total cholesterol, LDL-cholesterol and FFA $(\mathrm{mmol} / \mathrm{L})$ of GA-treated rats showed reduction after seven days of oral GA administration while that of HDL-cholesterol showed an increase ( $p>0.05$ for all parameters).

0.05). Among the muscles, the QF and the AM showed significantly reduced lipid deposition in the GA-treated group relative to the control $(p<0.05)$, with a decrease of $42.21 \%$ and $33.96 \%$ in each tissue respectively (QF: control, 191.28 (28.85-606.17) AU; treated, 110.54 (12.21594.28); AM: control, 141.29 (11.77-356.51) AU; treated, 93.31 (22.69-297.13) AU). Lastly, lipid deposi-

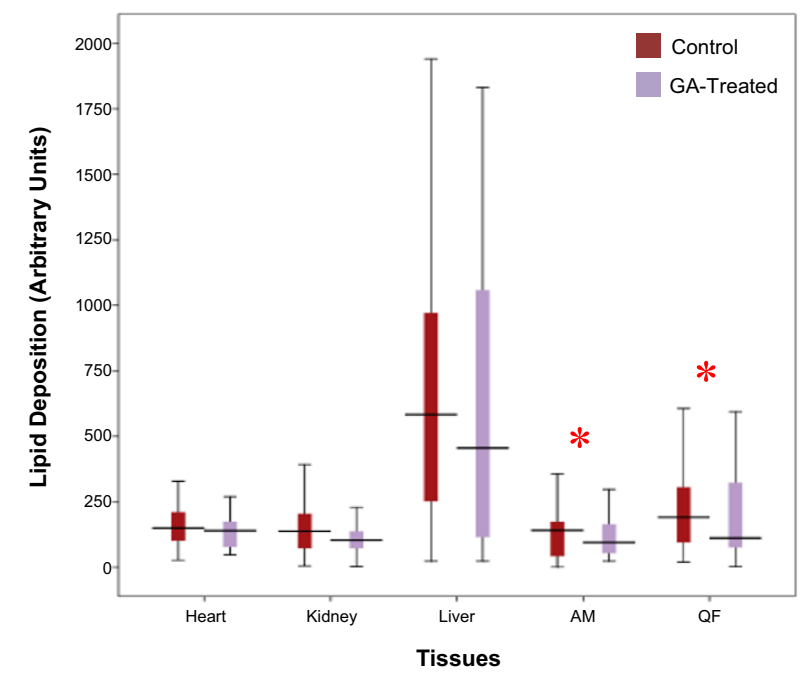

Figure 5

Levels of lipid deposition in non-adipose tissues. Sections of ORO-stained tissues were converted to a grayscale each time for lipid staining quantification. * denotes $p<0.05$. tion in the heart showed a non-significant $6.74 \%$ decrease (control, 149.56 (26.58-327.91) AU; treated, 139.48 (47.74-268.54) AU). Sections of these tissues are depicted in Figure 6.

\section{GA treatment did not induce an increase in systolic blood pressure}

Systolic blood pressure of control and GA-treated rats fluctuated within a narrow range throughout the duration

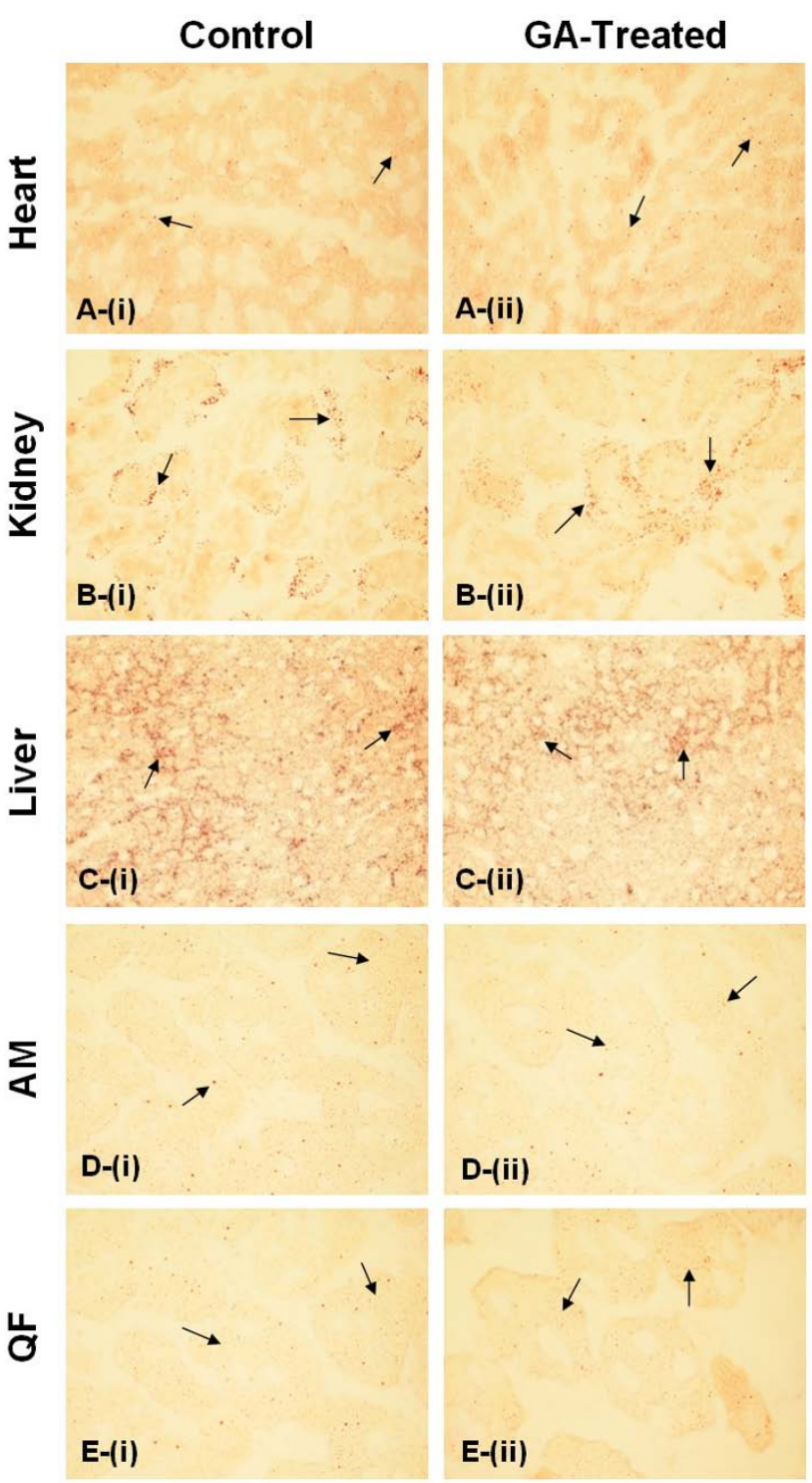

Figure 6

ORO-stained tissues. Representative sections of OROstained (A) heart, (B) kidney, (C) liver, (D) AM and (E) QF in (i) control and (ii) treated rats at $400 \times$ magnification. Distinct spots of ORO-stained lipid were observed across all tissue sections with considerable heterogeneity in lipid content between tissues. Arrows indicate examples of lipid droplets. 
of treatment (Figure 7). Systolic blood pressure of the control and GA-treated rats were compared on Days 0, 2, 4 and 6 of the treatment duration. No significant difference $(p>0.05)$ in mean systolic blood pressure was observed between the control and treated groups and within each group on each of these days.

\section{Discussion}

IR has been recognized as the central component of the MetS which is associated with hyperinsulinaemia, glucose intolerance, dyslipidaemia and visceral obesity [4]. With the onset of IR, the activity of LPL, a key regulator of lipoprotein metabolism that is subject to insulin regulation, has been reported to be reduced both in the adipose tissues and muscles $[18,19]$. Insulin has been implicated in the biosynthesis of LPL [10] where the insulin-signaling pathway activates the class of nuclear receptors known as the peroxisome proliferator-activator receptor (PPAR). The isoforms of these, PPAR $\alpha$ and PPAR $\gamma$, then bind to the peroxisome proliferator respondse element (PPRE) at the LPL gene promoter to up-regulate LPL expression [20].

In this study, inhibition of $11 \beta$-HSD 1 by GA could not account adequately for the observed increase in tissue LPL expression. Despite the inhibitory effects of glucocorticoids on LPL protein synthesis and mRNA levels, such observations were only observed in the adipose tissues [21]. Therefore, the induction of LPL expression in this study points to a separate mode of action of GA where GA is postulated to activate the PPAR class of nuclear recep-

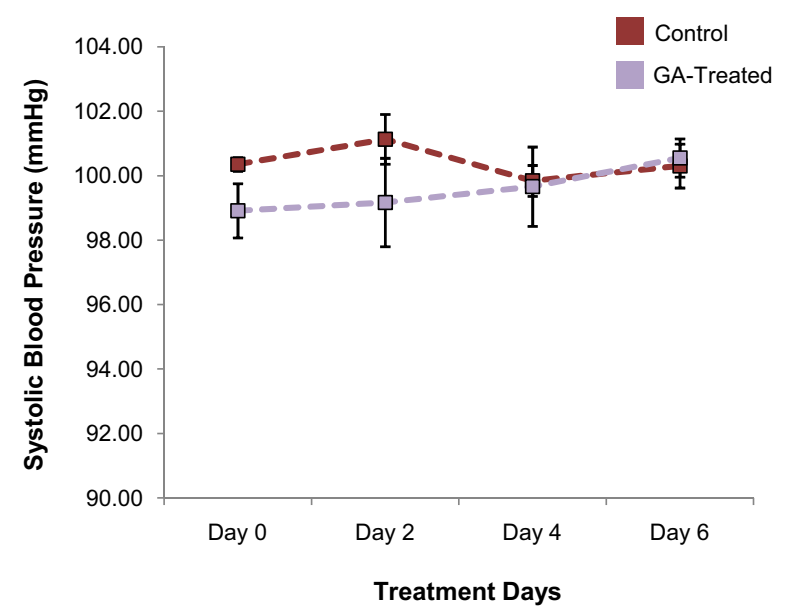

\section{Figure 7}

Evaluation of systolic blood pressure. Day-to-day mean systolic blood pressure $(\mathrm{mmHg})$ of control and treated rats over the duration of treatment. No significant difference was observed in each of the days between both groups and within each group $(p>0.05)$. tors. This is based on the consistency of several findings, where (i) triterpenoids have been reported to lead to the transactivation of PPAR- $\gamma[22,23]$ and more importantly (ii) PPAR- $\alpha$ and $-\gamma$ agonists have been shown to reduce the expression and activity of $11 \beta$-HSD 1 [24]. Thus, GA, both a triterpenoid and an $11 \beta$-HSD 1 inhibitor may act as a ligand to the PPAR. Interestingly, $11 \beta$-HSD 1 knock-out mice also show an elevation of PPAR- $\alpha$ mRNA. PPAR- $\alpha$ is physiologically induced by glucocorticoids and its elevation following $11 \beta$-HSD1 inhibition may have arisen from increased circulating plasma corticosterone due to impaired 11 $\beta$-HSD1-mediated negative feedback upon the hypothalamic-pituitary-adrenal axis [14]. This increased PPAR $\alpha$ may then act in return to up-regulate LPL. Thus, GA-mediated activation of the PPAR class of nuclear receptors may be direct or indirect.

PPAR- $\alpha$ plays a key role in regulating pathways of $\beta$-oxidation and is expressed abundantly in tissues metabolizing high amounts of FFA, such as the liver, kidney, heart and muscles while PPAR- $\gamma$ is expressed primarily in the adipose tissues where it triggers adipocyte differentiation and lipogenesis $[25,26]$. With reference to Figure 1, increased LPL expression was consistently higher in tissues characterized by high PPAR- $\alpha$ expression (QF, AM, kidney and liver) as compared to tissues in which PPAR- $\gamma$ predominates (VAT and SAT). One exception however was seen in the heart that has a relative LPL expression comparable to that of the adipose tissues. Such discrepancy may be due to the lower distribution of GA into the heart as compared to all other tissues examined in this study [27]. The selective pattern of tissue LPL induction suggested that GA exhibits greater potency in activating PPAR- $\alpha$ than PPAR$\gamma$. Such pattern of tissue LPL induction have been advocated for the correction of visceral obesity as it could lead to the competitive delivery of FFA away from the more pathogenic visceral fat depot to other less pathogenic depots [28].

This postulation was then confirmed in the study through the measurement of adipocyte size in both control and GA-treated rats. With reference to Figure 2, size of adipocytes exhibited a decrease in both the VAT and SAT following GA treatment. The overall results have therefore shown that by reducing visceral fat accumulation, GA has the potential to counteract the very fundamental abnormality that contributes to the development of the MetS, i.e. visceral obesity [8].

Accompanying the increase in tissue LPL expression and decrease in adipocyte size was the consistent improvement in serum lipid parameters of the GA-treated rats relative to the control; with a reduction in serum FFA, TAG, total cholesterol and LDL-cholesterol and elevation of HDL-cholesterol. The GA-induced decrease in serum FFA 
appears to be of critical importance due to the role of FFA in initiating the development of IR, $\beta$-cell dysfunction and dyslipidaemia [5,7]. The observed decrease in serum FFA may be attributed to increased tissue uptake. Berthiaume et al. [29] has demonstrated that inhibition of 11 $\beta$-HSD1 is associated with a concomitant increase in protein content of plasma membrane fatty acid-binding protein $\left(\mathrm{FABP}_{\mathrm{pm}}\right)$ that facilitates the entry of FA into cells. In addition, PPAR- $\alpha$ agonists have also been reported to induce the activities of fatty acid transporter protein (FATP) and acyl-CoA synthetase [30], where the former mediates FFA uptake and the latter is involved in the activation of FFA that then facilitates its $\beta$-oxidation $[31,32]$. Activation of acyl-CoA synthetase therefore promotes the oxidation of FFA to prevent the saturation of cellular FA binding and transport [32]. This supports further the decrease in lipid deposition in the studied tissues despite increased FFA uptake.

The decrease in serum TAG did not appear secondary to the reduction in serum FFA and may be mostly attributed to the action of GA. Inhibition of $11 \beta$-HSD 1 has been shown to reduce hepatic VLDL secretion [29] which may have been driven by increased hepatic FFA oxidation due to the induced expression of fat-catabolizing enzymes [14]. Hepatic VLDL secretion is regulated by the amount of lipids available for the assembly of VLDL [29]. Extracellular FFA entering the liver is either oxidized or esterified to form a cytosolic pool of TAG; the TAG required for VLDL assembly is recruited from this pool. Physiologically, extracellular FFA acts to boost VLDL secretion by expanding the size of this intrahepatic TAG pool [33]. With increased FA oxidation however, the drive for the VLDL assembly pathway is subsequently attenuated.

The increase in HDL-cholesterol following GA administration may be due to the increased production of apo AI, the major protein of HDL that is subjected to accelerated catabolism in the MetS [7]. Apo A-I mRNA has been shown to be significantly elevated in $11 \beta$-HSD 1 knockout mice [14] and following PPAR- $\alpha$ activation [30]. Since the rate of HDL synthesis is dependent on the production of apo A-I [34], this has been speculated as the HDLincreasing mechanism of GA.

Despite lacking benefits of increased LPL expression in this study, such LPL induction by GA may be pivotal in the amelioration of lipid parameters in dyslipidaemic subjects. In the lean rats employed in this study, the serum TAG measured after a 12-h fast reflects only the VLDL fraction. Serum chylomicrons have a half life of 13-14 minutes and would be cleared from circulation within this fasting period [35]. In dyslipidaemic subjects however, hypertriglyceridaemia is attributed to the prolonged retention of both chylomicrons and VLDL due to inhib- ited lipolysis of both particles following decreased LPL levels [8]. Therefore, in the dyslipidaemic state, induced LPL may contribute to the increased clearance of such lipoproteins to reduce serum TAG. Furthermore, the development of small, dense LDL and the reduction in HDL seen in the dyslipidaemic state are attributed to CETP-mediated lipid exchange between both lipoprotein particles and TAG-enriched VLDL particles. Such exchange is substrate-rather than enzyme-driven [36]. The increased catabolism of TAG-enriched VLDL by LPL may thus serve to positively re-modulate HDL and LDL profile in dyslipidaemia.

The observed decrease in lipid deposition across all studied tissues may be consequential of increased lipid oxidation in these tissues following GA administration. Previous reports have suggested that increased tissue lipid content in the obese state is related to decreased activity of oxidative enzymes [12]. In this study, increase in enzymes of $\beta$-oxidation such as acyl-CoA synthetase, mitochondrial carnitine palmitoyltransferase-I and acyl-CoA oxidase were postulated to be induced through (i) direct activation of PPAR- $\alpha$ by GA, (ii) increased expression of PPAR- $\alpha$ following inhibition of $11 \beta$-HSD1 [14], or (iii) activation of PPAR- $\alpha$ by LPL-generated FFA that serves as natural PPAR- $\alpha$ ligands [37]. All the enzymes aforementioned carry a PPRE in the promoter region [30,38,39]. The last postulation showed consistency with the results of the study where significant decrease in lipid deposition was observed in the AM and QF, in agreement with their higher increase in LPL expression compared to all other tissues. In addition to the current study, Berthiaume et al. [29] has also demonstrated that inhibition of $11 \beta$-HSD1 was associated with a reduction in tissue TAG content and increased FFA oxidation.

TAG is present in all cell types and intracellular storage of these neutral lipids occurs within lipid droplets. The adipose tissue and liver are the principal stores of TAG, explaining the high levels of lipid deposition in the liver, while other cell types store small quantities of these. Tissue TAG storage occurs in any quantities, and in the liver for example, TAG storage may range up to 10-fold [33]. This explains the large range of lipid deposition in tissues as observed in the study.

Obesity and T2DM has been associated with tissue lipid accumulation and such ectopic TAG accumulation, also known as tissue steatosis, is implicated in the impairment of insulin signaling $[12,13]$. These lipotoxic effects are not exerted by TAG itself, but through TAG-derived bioactive lipid metabolites such as long chain fatty acyl-CoA, diacylglyerol and ceramide that activate several serine kinases to block insulin signal transduction [26]. In addition, lipid accumulation in the pancreatic islets would further 
impair insulin secretion where both ceramide and the nitric oxide generated from surplus unoxidized FFA induces $\beta$-cell apoptosis in the pancreatic islet [5]. T2DM has been postulated to only develop in such setting of concurrently occurring IR and $\beta$-cell failure [40]. With the demonstrated ability of GA to reduce tissue TAG accumulation therefore, GA exhibits the potential to revert such lipotoxicity exerted by tissue TAG excess and thereby serve to prevent the onset of T2DM.

The analysis of systolic blood pressure was conducted to determine the occurrence of the reported side effects of GA intake. Chronic administration of GA has been associated with the development of pseudoaldosteronism, of which includes symptoms such as electrolyte imbalance and increased blood pressure. This results from the nonselective nature of both GA and GE that inhibits not only $11 \beta$-HSD1 but also $11 \beta$-HSD2 [17]. In this study, one week administration of GA did not induce an increase in systolic blood pressure. The positive effects arising from the inhibition of $11 \beta$-HSD 1 , such as modulation of serum lipid, that is more readily observable compared to the side effects arising from the inhibition of $11 \beta$-HSD2, such as an increase in blood pressure, is possibly due to different potency of GA in inhibiting the two isoforms of the enzyme. Shimoyama et al. [41] has reported that GE, the active metabolite of GA, is more effective in inhibiting $11 \beta$-HSD1 than $11 \beta$-HSD2. The $\mathrm{IC}_{50}$ for the two enzymes are $0.09 \mu \mathrm{M}$ and $0.36 \mu \mathrm{M}$ respectively. This may signify that the impact of GA on systolic blood pressure may be observed if treatment duration was prolonged, or by increasing the treatment dosage within the same duration. Nevertheless, Quaschning et al. [42] has demonstrated that the use of aldosterone and endothelin receptor antagonists could normalize GA-induced blood pressure. The combinatorial use of GA and such antagonists may therefore represent a new therapeutic approach for patients with MetS; allowing patients to harbour the benefits from GA itself and simultaneously eliminating the possible side effects.

\section{Conclusion}

Daily oral administration of $50 \mathrm{mg} / \mathrm{kg}$ of GA for a week led to increased LPL expression predominantly in the non-adipose tissues, with significant increase in the QF. Together with the reduction in size of adipocytes in both the VAT and SAT, this may suggest that GA could divert FFA away from the pathogenic visceral depot to the oxidative tissues, thus curbing visceral obesity. GA also modulated serum lipid and the consistent pattern of improvement of each lipid parameter; namely, serum FFA, TAG, total cholesterol, HDL-cholesterol and LDLcholesterol, points to the ability of GA to cause a beneficial shift to a less atherogenic lipid profile. The decrease in tissue lipid deposition across all the non-adipose tissues studied indicated that lipid did not accumulate in these despite increased LPL expression, possibly due to an accompanying increase in $\beta$-oxidation. GA may therefore retard the development of IR associated with tissue steatosis.

\section{Methods \\ Animals and treatment}

The use and handling procedure of animals in this research project had been approved by the Monash University Animal Ethics Committee (AEC Approval Number: SOBSB/MY/2007/22). 16 male Rattus norvegicus SpragueDawley rats weighing between 160-200 g were supplied by Universiti Malaya Animal House (Malaysia) and were housed individually in polypropylene cages in a room kept at $23^{\circ} \mathrm{C}$ on a 12 -h light: 12 -h dark cycle (lights on at 0800 hours). The rats were randomly segregated into two groups of eight; representing the control and GA-treated groups. The GA-treated group was given $50 \mathrm{mg} / \mathrm{kg}$ of GA daily per oral (p.o.) while the control group given tap water without GA. All animals were fed ad libitum with free access to standard rat chow (Glenn Forrest Stockfeeder, Australia) and drinking water for the one week duration of treatment.

\section{Systolic blood pressure measurement}

Systolic blood pressure was measured by tail cuff plethysmography using the NIBP controller (ADInstruments, Australia). Conscious rats were placed into a plastic restrainer and a tail-cuff with a pulse transducer was applied onto the tail. The tail was heated using a table lamp. Rats were allowed to habituate to the procedure for 7 days prior to start of the experiment. The recording and determination of blood pressure were performed using the Chart recording software and a final reading was averaged out from at least 10 consecutive readings. This procedure was performed every alternate day.

\section{Blood and tissue sampling}

At the end of the treatment period, all rats were humanely sacrificed between 0800 to 1000 hours on the $8^{\text {th }}$ day of treatment after a 12-h fast. All rats were anaesthetized via intraperitoneal injection of $150 \mathrm{mg} / \mathrm{kg}$ of sodium pentobarbital (Nembutal) prior to exsanguination. Blood was drawn from the cardiac ventricle via the apex and was centrifuged at $12,000 \times \mathrm{g}$ for 10 minutes. The resulting serum supernatant was then rapidly aliquoted into microtubes and kept frozen at $-80^{\circ} \mathrm{C}$ until required for analysis. The seven tissues of interest; heart, liver, kidney, AM, QF and VAT and SAT were promptly harvested, all of which were placed into individual cryovials (Nalgene, USA) and immediately snap-frozen in liquid nitrogen. These were then stored at $-80^{\circ} \mathrm{C}$ until required for analysis. In addi- 
tion, a fraction of VAT and SAT were immersed in $10 \%$ neutral-buffered formalin in individual universal bottles for histological analysis.

\section{Plasma lipid parameters}

Total cholesterol, TAG and FFA were measured with Randox CH200 Cholesterol kit (Randox, UK), Wako Triglyceride E kit (Wako, Japan) and Randox FA115 NonEsterified Fatty Acids kit (Randox, UK) respectively. To determine the level of HDL-cholesterol, HDL-cholesterol was first separated from the LDL and VLDL fraction by precipitation of the latter two using the Randox $\mathrm{CH} 203$ HDL Precipitant (Randox, UK), followed by a cholesterol assay using the Randox CH200 Cholesterol kit (Randox, UK). LDL-cholesterol was calculated using the Friedewald formula, using the levels of total cholesterol, TAG and HDL cholesterol obtained [43].

\section{RNA extraction and cDNA synthesis}

Total RNA extraction of the heart, liver, kidney, AM and QF was performed using the Qiagen RNeasy Mini Kit (Qiagen, USA) while that of the VAT and SAT with the Qiagen RNeasy Lipid Tissue Mini Kit (Qiagen, USA). RNA purity was performed by measuring the absorbance of the diluted RNA at 260 and $280 \mathrm{~nm}$. RNase-free DNase treatment was performed using Promega RQ1 RNase-free DNase (Promega, USA) and cDNA synthesis was performed using the Qiagen Omniscript Reverse Transcriptase kit (Qiagen, USA).

\section{Real time reverse transcription polymerase chain reaction (qRT-PCR)}

The expression of LPL was determined by qRT-PCR using the LPL forward and reverse primers 5'-CAGCAAGGCATACAGGTG-3' and 5'-CGAGTCTTCAGGTACATCTTAC-3' and the probe 5'-(6-FAM) TTCTCTTGGCTCTGACC (BHQ1)-3' that are specific for Rattus norvegicus LPL mRNA [GenBank: $\underline{\mathrm{BC} 081836}$ ] and normalized to the $\beta$ actin (BAC) gene with the forward and reverse primers 5'GTATGGGTCAGAAGGACTCC-3' and 5'-GTTCAATGGG GTACTTCAGG-3' and the probe 5'-(TET) CCTCTCTTGCTCTGGGC (BHQ1)-3' specific for Rattus norvegicus BAC mRNA [GenBank: BC063166]. The comparison of LPL expression between control and GA-treated rats were performed using the Comparative $\mathrm{Ct}(\Delta \Delta \mathrm{Ct})$ Method, with BAC as reference, GA-treated group as target and control group as calibrator. Agarose gel electrophoresis was carried out on amplicons generated from qRT-PCR reaction to ensure primer specificity.

\section{Tissue lipid staining}

Frozen tissues were cut into small cubes of approximately $5 \times 5 \times 5 \mathrm{~mm}$ on and embedded using the Optimal Cutting Temperature (OCT) Compound (Leica, Germany).
Cryosectioning was performed at a temperature of $-25^{\circ} \mathrm{C}$ where the embedded tissues were sectioned into $5 \mu \mathrm{m}$ slices and adhered onto glass slides. Staining with Oil Red $\mathrm{O}(\mathrm{ORO})$ was performed in accordance to Koopman et al. [44] and captured at 400× magnification. Lipid deposition was quantified as specified by Goodpaster et al. [12]. Images were transferred to Image J software and converted to grayscale. Threshold for the intensity of staining was adjusted in order to pick up only the droplets of lipid; the full-range being from 0 to 255 arbitrary units (AU), where 0 represents complete staining and 255 represents no staining. For lipid quantification, pixels with intensities of $\leq 150 \pm 30$ AU were quantified. Lipid deposition were expressed in AU and calculated as:

Lipid Deposition $=\frac{\text { Percentage of area stained } \times \text { Mean intensity of staining }}{10^{6}}$

Eight contiguous views per tissue section were captured and analyzed for the lipid content. The level of lipid deposition of each tissue section was calculated as the average of these eight values.

\section{Morphometric analysis of adipocytes}

Adipose tissues that were fixed in 10\% neutral-buffered formalin as aforementioned were processed by a Leica TP 1020 Automatic Tissue Processor and embedded in paraffin. $5 \mu \mathrm{m}$ thick tissue sections were then stained with haematoxylin and eosin (H\&E) followed by the measurement of the size of 100 adipocytes $\left(\mu \mathrm{m}^{2}\right)$ per field view per tissue section at $100 \times$ magnification.

\section{Statistical analysis}

Statistical analysis of LPL expression was performed using the Relative Expression Software Tool (REST ${ }^{\circ}$ ) MCS Beta 2006 while that of all other parameters was performed using the Statistical Package for the Social Sciences (SPSS) Version 16.0. Data distribution was analyzed using the Kolmogorov-Smirnov test. Parametric data were then analyzed with independent $t$-test and are presented as mean \pm standard error while non-parametric with Mann-Whitney U-test and are reported as median (minimum - maximum). In all analyses, a $p$-value $\leq 0.05$ was considered significant.

\section{Abbreviations}

11 $\beta$-HSD: $11 \beta$-hydroxysteroid dehydrogenase; AM: abdominal muscle; CETP: cholesteryl ester transfer protein; FFA: free fatty acids; GA: glycyrrhizic acid; GE: glycyrrhetic acid; H\&E: haematoxylin and eosin; HL: hepatic lipase; HDL: high-density lipoprotein; IR: insulin resistance; LDL: low-density lipoprotein; LPL: lipoprotein lipase; MetS: metabolic syndrome; ORO: Oil Red O; PPAR: peroxisome proliferator-activator receptor; PPRE: peroxisome proliferator response element; QF: quadri- 
ceps femoris; SAT: subcutaneous adipose tissue; T2DM: type 2 diabetes mellitus; TAG: triacylglycerol; VAT: visceral adipose tissue; VLDL: very-low-density lipoprotein.

\section{Competing interests}

The authors declare that they have no competing interests.

\section{Authors' contributions}

WYAL was involved in all bench work, data acquisition, analysis and interpretation and manuscript preparation. YYC had part in the optimization of the qRT-PCR conditions and SYL had part in histological work. SHT, KAK and SNASH participated in the coordination of the study and helped in drafting the manuscript. All authors read and approved the final manuscript.

\section{Acknowledgements}

The study is funded in part by a grant from the Malaysian Ministry of Science, Technology and Innovation (02-02-10-SF0003).

\section{References}

I. Preiss-Landi K, Zimmermann R, Hammerle G, Zechner R: Lipoprotein lipase: the regulation of tissue specific expression and its role in lipid and energy metabolism. Curr Opin Lipidol 2002, | 3(5):47|-48|.

2. Pillarisetti S, Saxena U: Lipoprotein lipase as a therapeutic target for dyslipidemia. Front Biosci 2003, 8: d238-24I.

3. Balkau B, Valensi P, Eschwege E, Slama G: A review of the metabolic syndrome. Diabetes Metab 2007, 33:405-4I3.

4. Fulop T, Tessier D, Carpentier A: The metabolic syndrome. Pathologie Biologie 2006, 54:375-386.

5. Boden G, Shulman GI: Free fatty acids in obesity and type 2 diabetes: defining their role in the development of insulin resistance and beta-cell dysfunction. Eur J Clin Invest 2002, 32(3): $14-23$

6. Krauss R: Lipids and Lipoproteins in Patients With Type 2 Diabetes. Diabetes Care 2004, 27(6): I496-1504.

7. Kolovou GD, Anagnostopoulou KK, Cokkinos DV: Pathophysiology of dyslipidaemia in the metabolic syndrome. Postgrad Med J 2005, 8I:358-366.

8. Lann D, LeRoith D: Insulin Resistance as the Underlying Cause for the Metabolic Syndrome. Med Clin N Am 2007, 9 I : I 063- 1077.

9. Mead JR, Irvine SA, Ramji DP: Lipoprotein lipase: structure, function, regulation and role in disease. I Mol Med 2002, 80:753-769.

10. Kageyama H, Hirano T, Okada K, Ebara T, Kageyama A, Murakami T, Shioda S, Adachi M: Lipoprotein lipase mRNA in white adipose tissue but not in skeletal muscle is increased by pioglitazone through PPAR-gamma. Biochem Biophys Res Commun 2003, 305:22-27.

II. Aguilera CM, Gil-Campos M, Canete R, Gil A: Alterations in plasma and tissue lipids associated with obesity and the metabolic syndrome. Clin Sci 2008, I I 4:183-193.

12. Goodpaster BH, Theriault R, Watkins SC, Kelley DE: Intramuscular Lipid Content Is Increased in Obesity and Decreased by Weight Loss. Metabolism 2000, 49(4):467-472.

13. Athenstaedt K, Daum G: The life cycle of neutral lipids: synthesis, storage and degradation. Cellular and Molecular Life Sciences 2006, 63:1355-1369.

14. Morton MM, Holmes MC, Fievet C, Staels B, Tailleux A, Mullins J], Seckl JR: Improved Lipid and Lipoprotein Profile, Hepatic Insulin Sensitivity and Glucose Tolerance in I I betaHydroxysteroid Dehydrogenase Type I Null Mice. J Biol Chem 200I, 276(44):4I293-4I300.

15. Livingstone DEW, Walker BR: Is I I beta-Hydroxysteroid Dehydrogenase Type I a Therapeutic Target? Effects of Carbenoxolone in Lean and Obese Zucker Rats. J Pharmacol Exp Ther 2003, 305(I):167-172.
16. Alberts P, Engblom L, Edling N, Forsgren M, Klingstrom G, Larsson C, Ronquist-Nii Y, Ohman B, Abrahmsen L: Selective inhibition of Il beta-hydroysteroid dehydrogenase type I decreases blood glucose concentrations in hyperglycaemic mice. Diabetologia 2002, 45: I528-1532.

17. Wamil M, Seckl JR: Inhibition of I Ibeta-hydroxysteroid dehydrogenase type I as a promising therapeutic target. Drug Discov Today 2007, I 2(13//4):504-520.

18. Pollare T, Vessby B, Lithell $\mathrm{H}$ : Lipoprotein lipase activity in the skeletal muscle is related to insulin sensitivity. Arterioscler Thromb Vasc Biol I991, I I: I 192-1203.

19. Kern P: Potential Role of TNF-alpha and Lipoprotein Lipase as Candidate Genes for Obesity. J Nutr 1997, I27:1917S-1922S.

20. Hanyu O, Miida T, Obayashi K, Ikarashi T, Soda S, Kaneko S, Hirayama S, Suzuki K, Nakamura Y, Yamatani K, Aizawa Y: Lipoprotein lipase (LPL) mass in preheparin serum reflects insulin sensitivity. Atherosclerosis 2004, 1 74:385-390.

21. Enerback S, Gimble JM: Lipoprotein lipase gene expression: physiological regulators at the transcriptional and post-transcriptional level. Biochim Biophys Acta 1993, I 169:107-125.

22. Wang Y, Porter WW, Suh N, Honda T, Gribble GW, Leesnitzer LM, Plunket KD, Mangelsdorf DJ, Blanchard SG, Willson TM, Sporn MB: A Synthetic Triterpenoid, 2-Cyano-3,12-dioxooleana-1,9dien-28-oic Acid (CDDO), Is A Ligand for the Peroxisome Proliferator-Activated Receptor Gamma. Mol Endocrinol 2000, I4( I 0): I550-I556.

23. Sato M, Tai T, Nunoura Y, Yajima Y, Kawashima S, Tanaka K: Dehydrotrametenolic Acid Induces Preadipocyte Differentiation and Sensitizes Animal Models of Noninsulin-Dependent Diabetes Mellitus to Insulin. Biol Pharm Bull 2002, I 5(I):8I-86.

24. Hermanowski-Vosatka A, Balkovec JM, Cheng K, Chen HY, Hernan$\operatorname{dez}$ M, Koo GC, Le Grand CB, Li Z, Metzger JM, Mundt SS, Noonan $\mathrm{H}$, Nunes CN, Olson SH, Pikounis B, Ren N, Robertson N, Schaeffer JM, Shah K, Springer MS, Strack AM, Strowski M, Wu K, Wu T, Xiao J, Zhang BB, Wright SD, Thieringer R: I Ibeta-HSDI inhibition ameliorates metabolic syndrome and prevents progression of atherosclerosis in mice. J Exp Med 2005, 202(4):5।7-527.

25. Berger J, Tanen M, Elbrecht A, Hermanowski-Vosatka A, Moller DE, Wright SD, Thieringer R: Peroxisome Proliferator-activated Receptor-gamma Ligands Inhibit Adipocyte Il lbetaHydroxysteroid Dehydrogenase Type I Expression and Activity. J Biol Chem 200I, 276(16): 12629-12635.

26. Muoio DM, Newgard CB: Obesity-Related Derangements in Metabolic Regulation. Annu Rev Biochem 2006, 75:367-40I.

27. Ishida S, Sakiya Y, Ichikawa T, Taira Z, Awazu S: Prediction of Glycyrrhizin Disposition in Rat and Man by a Physiologically Based Pharmacokinetic Model. Chem Pharm Bull 1990, 38(I):212-218.

28. McCarty M: Modulation of adipocyte lipoprotein lipase expression as a strategy for preventing or treating visceral obesity. Med Hypotheses 200I, 57(2): 192-200.

29. Berthiaume M, Laplante M, Festuccia WT, Cianflone K, Turcotte LP, Joanisse DR, Olivecrona G, Thieringer R, Deshaies Y: I I beta-HSD I inhibition improves triglyceridaemia through reduced liver VLDL secretion and partitions lipids towards oxidative tissues. Am J Physiol Endocrinol Metab 2007, 293:EI045-EI052.

30. Staels B, Dallongeville J, Auwerx J, Schoojans K, Leitersdorf E, Fruchart JC: Mechanisms of Action of Fibrates on Lipid and Lipoprotein Metabolism. Circulation 1998, 98:2088-2093.

31. Elliot WH, Elliot DC: Energy release from fat. In Biochemistry and Molecular Biology 3rd edition. Oxford: Oxford University Press; 2005:226-232.

32. Doege H, Stahl A: Protein-Mediated Fatty Acid Uptake: Novel Insights from In Vivo Models. Physiology 2006, 21 :259-268.

33. Gibbons GF, Islam K, Pease RJ: Mobilisation of triacylglycerol stores. Biochim Biophys Acta 2000, I 483:37-57.

34. Dullens SPJ, Plat J, Mensink RP: Increasing apo A-I production as a target for CHD risk reduction. Nutr Metab Cardiovas 2007, 17:616-628.

35. Gurr MI, Harwood JL, Frayn KN: Lipid transport. In Lipid Biochemistry: An Introduction 5th edition. Oxford: Blackwell Science; 2002: $170-212$

36. Tan KCB, Shiu SWM, Chu BYM: Roles of hepatic lipase and cholesteryl ester transfer protein in determining low density lipoprotein subfraction distribution in Chinese patients with 
non-insulin-dependent diabetes mellitus. Atherosclerosis 1999 , I 45:273-278.

37. Koike T, Liang J, Wang X, Ichikawa T, Shiomi M, Liu G, Sun H, Kitajima S, Morimoto M, Watanabe T, Yamada N, Fan J: Overexpression of Lipoprotein Lipase in Transgenic Watanabe Heritable Hyperlipidemic Rabbits Improves Hyperlipidemia and Obesity. J Biol Chem 2004, 279(9):752I-7529.

38. Leiji FR van der, Huijkman NCA, Boomsma C, Kuipers JRG, Bartelds B: Genomics of the Human Carnitine Acyltransferase Genes. Mol Genet Metab 2000, 7I:I39-I53.

39. Kane CD, Francone OL, Stevens KA: Differential regulation of the cynomolgus, human, and rat acyl-CoA oxidase promoters by PPAR-alpha. Gene 2006, 380:84-94.

40. Kim H, Ahn Y: Role of Peroxisome Proliferator-Activated Receptor-gamma in the Glucose-sensing Apparatus of Liver and Beta-cells. Diabetes 2004, 53(I):S60-S65.

4I. Shimoyama $Y$, Hirabayashi K, Matsumoto H, Sato T, Shibata S, Inoue $\mathrm{H}$ : Effects of glycyrrhetinic acid derivatives on hepatic and renal I Ibeta-hydroxysteroid dehydrogenase activities in rats. J Pharm Pharmacol 2003, 55:8II-8I7.

42. Quaschning T, Ruschitzka F, Niggli B, Lunt CMB, Shaw S, Christ M, Wehling M, Luscher TF: Influence of aldosterone vs endothelin receptor antagonism on renovascular function in liquoriceinduced hypertension. Nephrol Dial Transplant 200I, 16:2I46-2I5I.

43. Friedewald WT, Levy RI, Fredrickson DS: Estimation of the concentration of LDL-cholesterol in plasma without use of the preparative ultracentrifuge. Clin Chem 1972, 18:499-502.

44. Koopman R, Schaart G, Hesselink MKC: Optimisation of Oil Red $O$ staining permits combination with immunofluorescence and automated quantification of lipids. Histochem Cell Biol 200I, I 1 6:63-68.

Publish with Biomed Central and every scientist can read your work free of charge

"BioMed Central will be the most significant development for disseminating the results of biomedical research in our lifetime. "

Sir Paul Nurse, Cancer Research UK

Your research papers will be:

- available free of charge to the entire biomedical community

- peer reviewed and published immediately upon acceptance

- cited in PubMed and archived on PubMed Central

- yours - you keep the copyright

Submit your manuscript here:

http://www.biomedcentral.com/info/publishing_adv.asp
BiolMedcentral 